\title{
Thin film of guest-free type-II silicon clathrate on Si (111) wafer
}

Tetsuji Kume ${ }^{1}$, Fumitaka Ohashi ${ }^{1}$, Kentaro Sakai ${ }^{2}$, Atsuhiko Fukuyama ${ }^{3}$, Motoharu Imai $^{4}$, Haruhiko Udono ${ }^{5}$, Takayuki Ban ${ }^{1}$, Hitoe Habuchi ${ }^{6}$, Hidetoshi Suzuki ${ }^{3}$, Tetsuo Ikari $^{3}$, Shigeo Sasaki ${ }^{1}$, and Shuichi Nonomura ${ }^{1}$

${ }^{1}$ Faculty of Engineering, Gifu University, 1-1 Yanagido, Gifu, Japan;

${ }^{2}$ Center for Collaborative Research \& Community Cooperation, University of Miyazaki, 1-1 Gakuen Kibanadai-nishi, Miyazaki, Japan;

${ }^{3}$ Faculty of Engineering, University of Miyazaki, 1-1 Gakuen Kibanadai-nishi, Miyazaki, Japan;

${ }^{4}$ National Institute for Materials Science, Tsukuba, Ibaraki 305-0047, Japan;

${ }^{5}$ Graduate school of Science and Engineering, Ibaraki University, Hitachi, Ibaraki 316-8511, Japan;

${ }^{6}$ Department of Electrical and Computer Engineering, National Institute of Technology, Gifu College, Kamimakuwa 2236-2, Motosu, Gifu 501-0495, Japan

\begin{abstract}
Thin films of guest-free type-II Si clathrate (Si136) were fabricated on Si(111) wafers in two steps: $\mathrm{Na}_{x} \mathrm{Si}_{136}$ thin-film formation by thermal decomposition of $\mathrm{NaSi}$ precursor films and $\mathrm{Na}$ removal from the $\mathrm{Na}_{x} \mathrm{Si}_{136}$ film by a heat treatment with iodine. Cross-sectional TEM observation and XRD and Raman measurements verified the formation of $1-\mu \mathrm{m}$-thick Sil36 films on the Si wafer. Since the prepared films showed n-type conduction, pn junction devices were developed by a Si136/p-type Si structure. This device showed a photovoltaic (PV) response under white light illumination. The thin film formation and the PV response of $\mathrm{Si}_{136}$ indicated this $\mathrm{Si}$ allotrope to be the next-generation platform for semiconductor technology.
\end{abstract}




\section{Introduction}

Silicon is the most popular element in semiconductor technology. The most stable diamond-structure silicon ( $\mathrm{d}-\mathrm{Si})$ is an indirect bandgap semiconductor, which is not suitable for light emission and absorption device applications. However, Si continues to be one of the most important materials in the field of solar cells because it is one of the most abundant materials on earth. The $\mathrm{sp}^{3}$ bonding of Si tends to construct low-density open networks, giving rise to a wide variety of crystal structures. The Si allotropes with structures different from those of the diamond ones are still an attractive research subject [1-4]. Si clathrates [4-13] formed by a polyhedral Si-cage network are well-known examples of Si allotropes. Usually, the clathrate structures are stabilized with the aid of guest species in the cages, leading to distinct properties that address important issues in thermoelectric phonon glass-electron crystals $[14,15]$ and superconductivity [16, 17]. Conversely, the Si clathrate without guest species (guest-free Si clathrate) has for long attracted attention by the predicted band structure, which has a direct gap much wider than that of d-Si [6] and tunable in the visible region by alloying with $\mathrm{Ge}[5]$.

Thus, the guest-free type-II clathrate with a direct gap is a potential semiconducting material and is serviceable to thin-film solar cells. The guest-free type-II Si clathrate ( $\mathrm{Si}_{136)}$ and $\mathrm{Ge}$ clathrate $\left(\mathrm{Ge}_{136}\right)$ have been obtained experimentally [4,7-10,18]. However, there has been no report on their practical application to optoelectronic devices despite many studies on the type-II clathrates of Si [4,7-10,19-24], Ge [18], and Si-Ge alloys [25]. This is because it has been difficult to prepare films of clathrates. All the samples synthesized so far were in the powdered form. Recently, there have been several attempts to grow films of $\mathrm{Si}_{136}$ on $\mathrm{Si}$ wafers [23, 26, 27]. However, the synthesized powder-like samples, which adhere weakly to the substrate, were not sufficient for practical devices $[23,26]$. Although we have recently prepared film-like Si clathrate [27], the boundary of the Si clathrate and Si wafer was not well-investigated. The boundary is of much importance to the electrical contact, and its microscopic observation will give a hint to consider the crystal growth mechanism.

Here, we report the fabrication of a $1-\mu \mathrm{m}$-thick $\mathrm{Si}_{136}$ film adhering to a $\mathrm{Si}(111)$ wafer and an atomic-scale observation of the boundary of $\mathrm{Si}_{136}$ and $\mathrm{Si}$ wafer. The Si clathrate film was developed by thermal decomposition of the NaSi precursor film formed in advance on the $\mathrm{Si}(111)$ wafer. The $\mathrm{Na}$ atoms included in the as-prepared $\mathrm{Si}$ clathrate $\left(\mathrm{Na}_{x} \mathrm{Si}_{136}\right)$ were removed by iodine treatments [9], leading to the formation of the $\mathrm{Si}_{136}$

film. Cross-sectional high-resolution TEM observation demonstrated that there is no 
transition layer around the boundary of the $\mathrm{Si}_{136}$ and $\mathrm{Si}$ wafer. The prepared $\mathrm{Si}_{136}$ films were also examined by photovoltaic measurements by depositing ohmic electrodes on the films and on the back side of the Si wafer. Photovoltaic responses were confirmed under white light illumination.

\section{Experimental setup}

The Si clathrate films were prepared in a manner similar to that described in the literature [1, 4-5]. The Si wafers with (111) surfaces (Miyoshi, Japan: B doped p-type $\left(10^{-2} \Omega \cdot \mathrm{cm}\right)$, P-doped n-type $\left(10^{-2} \Omega \cdot \mathrm{cm}\right)$, and undoped $\left(10^{3} \Omega \cdot \mathrm{cm}\right), 20 \mathrm{~mm} \times 8 \mathrm{~mm} \times$ $0.5 \mathrm{~mm}$ mirror polished on one side) were washed by $\mathrm{HF}(\sim 5 \%)$ and deionized water. The wafers were horizontally placed $10 \mathrm{~mm}$ above the sodium slice (Sigma-Aldrich, Japan, 99\%) in a Ta crucible. The Ta crucible was placed in a sealed stainless-steel container under an Ar atmosphere (>99.999\%) and was heated for $48 \mathrm{~h}$ using a muffle furnace. The temperature was set to $580^{\circ} \mathrm{C}$ except for Sample $4\left(585^{\circ} \mathrm{C}\right)$. The Si wafers, which reacted with $\mathrm{Na}$ vapor to form $\mathrm{NaSi}$ on their surface, were taken out of the container under the Ar atmosphere and transferred into a vacuum furnace consisting of a quartz tube ( $80 \mathrm{~mm}$ in diameter and $1200 \mathrm{~mm}$ in length). The $\mathrm{NaSi}$ was then transformed into $\mathrm{Na}_{x} \mathrm{Si}_{136}$ by annealing at $400^{\circ} \mathrm{C}$ under vacuum conditions below $10^{-2}$ $\mathrm{Pa}$. The annealing duration was $3 \mathrm{~h}$ except for Sample $3(6 \mathrm{~h})$.

The $\mathrm{Na}$ included in the as-prepared $\mathrm{Na}_{x} \mathrm{Si}_{136}$ film was removed by a heat treatment with iodine $\left(I_{2}\right)$ vapor. The film on the Si wafer was put into a glass tube with $I_{2}$ powder separately. The glass tube was evacuated with a rotary pump and then sealed by melting a part of it. The sealed tube was heated at $450^{\circ} \mathrm{C}$ for $5 \mathrm{~h}$ using an electric furnace. The sample was washed with ethanol and pure water. This $\mathrm{I}_{2}$ treatment was repeated several times for each sample, as indicated in Table I.

The Si clathrate films were characterized by a cross-sectional TEM observation, XRD (Rigaku, SmartLab), and Raman spectroscopy (JASCO NRS2100G). The Na content in the sample was analyzed by SEM-EDX (Hitachi-4300). For electrical measurements, appropriate electrodes (indium tin oxide (ITO), Ag, and Al) were deposited on the Si clathrate film and on the bottom of the Si wafer; ITO was deposited by a sputtering method, and $\mathrm{Ag}$ and $\mathrm{Al}$ electrodes were deposited by vacuum evaporation. We prepared several types of samples using different types of Si wafers, electrodes, and Ar annealing conditions to establish an optimum device structure. The preparation conditions are listed in Table I. The electrical measurements were performed using an ammeter, which includes a voltage source (KEITHLEY 6517). The white light generated in a solar 
simulator illuminated the sample with a power density of $100 \mathrm{~mW} / \mathrm{cm}^{2}$ (AM1.5). All measurements were carried out at room temperature.

\section{Result and discussion}

A. Characterization of $\mathrm{Si}_{136}$ film

Figure 1(a) shows the typical microphotographs of an as-prepared $\mathrm{Na}_{x} \mathrm{Si}_{136}$ film on the $\operatorname{Si}(111)$ wafer. Two different morphologies were found on the surface: the green region was rather smooth and homogeneous, denoted here as region $\mathrm{A}$, and the black region was rough and powdery, denoted as region $\mathrm{B}$. The powder deposited on the $\mathrm{Si}$ wafer in region B was easily wiped out by a cotton bud and the bare Si wafer was exposed as shown in Fig. 1(b). However, the smooth film region A remained unchanged.

The lower panel of Fig. 1(c) shows the Raman spectrum of the film in region A. The spectrum was assigned as being from $\mathrm{Na}_{x} \mathrm{Si}_{136}$ by comparing the spectra of $\mathrm{Na}_{2.5} \mathrm{Si}_{136}$, Na6.1Si136, and Na13Si136 powders [22] shown in the top panel. The $520 \mathrm{~cm}^{-1}$ peak from the Si wafer was clearly observed. This means that the penetration depth of the probing light with $532 \mathrm{~nm}$ wavelength $(2.3 \mathrm{eV})$ is sufficiently larger than the thickness of the $\mathrm{Na}_{x} \mathrm{Si}_{136}$ clathrate. Considering a thickness of $1 \mu \mathrm{m}\left(10^{-4} \mathrm{~cm}\right)$ for the clathrate film, as discussed later, the absorption coefficient in this wavelength region was estimated to be on the order of $10^{4} \mathrm{~cm}^{-1}$ or smaller. The color gradations found in region A in Fig. 1(a) are explained by the interference fringes due to the small absorption coefficient and a film thickness that is comparable to the visible wavelength. The $\mathrm{Na}$ inclusion in the $\mathrm{Si}$ clathrate affects the relative Raman intensity of two sharp peaks in the lowest frequency region. As seen in the top panel of Fig. 1(c), the lower peak decreases in intensity as the $\mathrm{Na}$ content decreases from 13 to 2 . In region $\mathrm{A}$ of the present sample 1, the relative intensity of the lowest two peaks was similar to that of $\mathrm{Na}_{13} \mathrm{~S}_{136}$. Thus, the Na content, $x$, of the present Si clathrate film (region A) was roughly estimated to be around 10 .

The reduction in $\mathrm{Na}$ inclusions in the $\mathrm{Na}_{\mathrm{x}} \mathrm{S}_{136}$ film was conducted by repeated iodine treatments. Figure 2 indicates EDX spectra of the $\mathrm{Na}_{x} \mathrm{~S}_{136}$ film measured before and after the iodine treatments. Since the Na peak disappeared after the 3rd iodine treatment, the $\mathrm{Na}$ inclusion was not estimated. Considering the detection limit of EDX, the atomic ratio of $\mathrm{Na}$ to $\mathrm{Si}$ was only $0.5 \%$ at most $\left(x<0.68\right.$ for $\left.\mathrm{Na}_{x} \mathrm{Si}_{136}\right)$, even as per the largest estimation. Thus, we successfully prepared the guest-free $\mathrm{Si}$ clathrate $\left(\mathrm{Si}_{136}\right)$ thin film on the Si wafer. We also observed a strong peak of oxygen in the EDX spectra before and after the iodine treatments. The oxygen was considered to originate from the surface 
oxidation of the Si clathrate. The carbon peak was likely to arise from contamination due to the oil in the vacuum pumps.

The phase purity of the prepared film after the iodine treatments was analyzed by the XRD experiments with a grazing incidence of $\omega=1^{\circ}$. Figure 3 shows the XRD results of Sample 4 after the three-times-performed iodine treatment. Except for the peaks of the Ag electrode, all other observed peaks were well-assigned to the type-II Si clathrate. We observed neither $\mathrm{Na}_{8} \mathrm{Si}_{46}$ peaks (type I) nor d-Si peak, which was often observed as the minor phase in previous powdered samples developed by the thermal decomposition of NaSi [20]. Thus, the grazing incident XRD measurements confirmed that the synthesized film mainly consisted of $\mathrm{Si}_{136}$.

The $\mathrm{Si}_{136}$ film was observed in an atomic scale by a cross-section TEM technique. Figure 4(a) shows a typical low-resolution TEM image. A film with about $1 \mu \mathrm{m}$ in thickness was found to have grown on the Si wafer. There were two parts in the film. One was the crystalline part observed as a dark area and the other was the amorphous one found as a bright region. In the dark area, crystal lattice fringes were identified by the high-resolution TEM (HRTEM) observation (Fig. 4(b)). The crystalline parts consisted of crystal grains as small as $20-50 \mathrm{~nm}$ in size. The grains seemed to be randomly oriented. To confirm the crystal structure and discuss the crystal orientation, we simulated the TEM image of the guest-free type-II Si clathrate by using the multislice method originally developed by Cowley and Moodie [28]. The structural data of $\mathrm{Si}_{136}(\mathrm{Fd}-3 \mathrm{~m}, a=1.4626 \mathrm{~nm})$ reported in Refs. [4, 21] were used for the simulation. The inset of Fig. 4(c) is the simulated lattice image with the defocus of $-30 \mathrm{~nm}$ and the film thickness of $60 \mathrm{~nm}$ in the case of the electron beam entering along the $<011>$ direction. The image fits well with the observed HRTEM image, demonstrating that the Si clathrate films were successfully grown on the Si wafer.

Figure 4(d) shows a typical HRTEM image around the boundary between the Si clathrate and the Si wafer. Note here that the boundary appeared clearly, and there was no transition layer at the boundary. This implies that there are chemical bondings between the clathrate and the wafer. The inset indicates the fast Fourier transformation (FFT) of the lattice patterns, that is, the electron diffraction pattern of the Si clathrate and the wafer. For the Si wafer region, the diffractions were obtained only from $\mathrm{Si}(111)$. We also performed nano-beam electron diffraction (ED) measurements with the spot size of $25 \mathrm{~nm}$, simultaneously with the HRTEM observation, in order to determine the crystal orientation. As a result, this HRTEM image was found to be parallel to the directions of $\mathrm{Si}[111]$ and $\mathrm{Si}[4-51]$, as shown by the arrow in Fig. 3. The crystal orientation of the Si clathrate was identified by comparing the observed diffraction 
pattern with the theoretical ones simulated under various orientations. Each diffraction spot of Si clathrate was thus indexed as shown in the inset of Fig. 3. In this case, the direction [531] of Si clathrate was almost the same as that of $\mathrm{Si}[111]$, and the angle of tilt was just $2^{\circ}$. We found that Si clathrate [111], [422], and [004] directions were tilted toward $\mathrm{Si}[4-51]$ at 10,5 , and $10^{\circ}$ with respect to $\mathrm{Si}[111]$, respectively.

\section{B. Electrical properties of $\mathrm{Si}_{136}$ film}

The carrier type of the Sil36 film fabricated on the p-type Si wafer (Sample 4) was investigated by a hot-point probe method based on the thermoelectric power measurement. We found that the $\mathrm{Si}_{136}$ film was an n-type semiconductor. This is because the residual $\mathrm{Na}$ atoms in the $\mathrm{Si}_{136}$ film donate electrons. Thus, the direct contacts of the $\mathrm{Si}_{136}$ with p- and n-Si wafers may form a pn junction and an ohmic contact, respectively. We fabricated the $\mathrm{Si}_{136}$ films on various types of $\mathrm{Si}$ wafers, as listed in Table I, and developed several devices by depositing appropriate electrodes on the $\mathrm{Si}_{136}$ film and the back side of the wafer. The prepared device structures are shown in the insets of Figs. 5(a)-(d). In Fig. 5 (a), we can confirm an ohmic contact between the $\mathrm{Si}_{136}$ and $\mathrm{Ag}$ electrode. This is because a linear $\mathrm{I}-\mathrm{V}$ characteristic was confirmed between the coplanar Ag electrodes deposited on the Si136 film. On the other hand, a rectification property was found on the $\mathrm{Al} / \mathrm{p}-\mathrm{Si} / \mathrm{Si} 136 / \mathrm{Ag}$ system (Fig. 5(b)). The current was much higher when the $\mathrm{Al}$ was in the positive bias. This indicates the formation of a pn junction at the $\mathrm{Si}_{136} / \mathrm{p}-\mathrm{Si}$ interface because the contacts of $\mathrm{Al} / \mathrm{p}-\mathrm{Si}$ and $\mathrm{Si}_{136} / \mathrm{Ag}$ were both ohmic. The value of the diode factor $n$ was estimated to be 4.0 by fitting the experimental curve with the diode equation $I=I_{0}[\exp (q V / n k T)-1]$. Such a large $n$ value comes from carrier recombination in the pn junction region, which is due to the grain boundaries, impurities, and inhomogeneity in the present $\mathrm{Si}_{136}$ film.

The above pn junction system of $\mathrm{Si}_{136} / \mathrm{p}$-Si did not show the photovoltaic response because the Ag electrode blocked the light. Thus, we developed another device using a semi-transparent Ag thin film (about $\sim 10 \mathrm{~nm}$ in thickness) covered with an indium-tin oxide film as the top electrode (the inset of Fig. 5(c)). As seen in Fig. 5(c), the light illumination of AM1.5 shifted downward the I-V curve. Thus, we observed for the first time the photovoltaic response of the device developed from the $\mathrm{Si}_{136}$ film. The short-circuit current, open-circuit voltage, and photoelectric conversion efficiency were $9.2 \mathrm{nA}, 0.036 \mathrm{~V}$, and $10^{-5 \%}$, respectively.

Using an $n$-type Si wafer (Sample 3), we developed a Ag/Si136/n-Si/Al system for the ohmic device structure, as shown in the inset of Fig. 5(d). Although all contacts were intended to be ohmic, the I-V characteristic slightly deviated from the linear behavior at 
voltages higher than $0.5 \mathrm{~V}$. Using the linear part (the data measured at lower voltages $(-0.3<V<0.3))$, the electrical resistance $R$ was estimated to be $1.57 \times 10^{3} \Omega$. This value is essentially due to the $\mathrm{Si}_{136}$ film because the resistance components of the Si wafer and $\mathrm{Ag}$ and $\mathrm{Al}$ electrodes were assumed to be very small based on the literature (n-Si wafer: $\sim 10^{-2} \Omega \mathrm{cm}, \mathrm{Ag}: 1.63 \times 10^{-11} \Omega \mathrm{cm}$ [29], and Al: $2.7 \times 10^{-11} \Omega \mathrm{cm}$ [30]). Using an area of $3.9 \times 10^{-2} \mathrm{~cm}^{2}$ of the top electrode and a thickness of $1 \mu \mathrm{m}$ of the $\mathrm{Si}_{136}$ film, the electrical resistivity $(\rho)$ of the present $\mathrm{Si}_{136}$ film was estimated to be $10^{6} \Omega \mathrm{cm}$, which is comparable with the intrinsic d-Si $\left(\sim 10^{5} \Omega \mathrm{cm}\right)$.

Stefanoski et al. [24] reported the resistivity of single-crystalline $\operatorname{Na}_{x} \operatorname{Si}_{136}(x=14.7 \sim$ $2.9)$, which was very sensitive to the value of $x$. The $\rho$ was increased from $10^{-2} \Omega \mathrm{cm}$ to $4 \times 10^{-1} \Omega \mathrm{cm}$ when $x$ decreased from 5.1 to 2.9 . Following this tendency, the resistivity should be $10^{1}-10^{2} \Omega \mathrm{cm}$ for $x=0$. The value of $10^{6} \Omega \mathrm{cm}$ for the present $\mathrm{Si}_{136}$ film seems to be too high, even when taking into account the uncertainties for the estimated electrode sizes and film thickness. There is a possibility of overestimation of $\rho$ due to the inhomogeneity and the presence of an oxide layer. For a precise discussion on the electrical properties, we need higher-quality films having well-defined $\mathrm{Na}$ concentration. Investigations to clarify the electronic properties of Si clathrate are currently ongoing in our research group; the results will be published elsewhere.

\section{Conclusion}

Thin films of the guest-free type-II Si clathrate ( $\left.\mathrm{Si}_{136}\right)$ were fabricated on Si (111) wafers by heat treatment of the NaSi precursor films formed on the Si wafers followed by iodine treatments. The XRD measurements indicated that the prepared films consist of the single phase of Si136. The cross-sectional TEM observation demonstrated that the 1- $\mu$ m-thick Si136 film was grown on the Si(111) substrate. The PV response was observed in the pn junction devices with the $\mathrm{Si}_{136} / \mathrm{p}$-type $\mathrm{Si}$ structure. This is the first observation of the PV response in the device using Si clathrate, although the conversion efficiency was still low. The attempts to improve the conversion efficiency are now in progress in our research group. The fabrication of the Si clathrate thin film and the observation of its PV response indicated that this Si allotrope with a direct gap is the next-generation platform for semiconductor technology.

\section{Acknowledgments}

These experiments were conducted as a part of the Advanced Low Carbon Technology Research Project and Development Program (ALCA) with financial support received by the Japan Science and Technology Agency (JST). 
References

1. D. Y. Kim, S. Stefanoski, O. O. Kurakevych, T. A. Strobel, Nature Mat. 14 (2014) 169-173.

2. S. Ganguly, N. Kazem, D. Carter, S. M. Kauzlarich, J. Am. Chem. Soc. 136 (2014) 1296-1999.

3. S. Botti, J. A. Flores-Livas, M. Amsler, S. Goedecker, M. A. L. Marques, Phys. Rev. B 86 (2012) R121204.

4. J. Gryko, P. F. McMillan, R. F. Marzke, G. K. Ramachandran, D. Patton, S. K. Deb, O. F. Sankey, Phys. Rev. 62 (2000) R7707.

5. K. Moriguchi, S. Munetoh, A. Shintani, Phys. Rev. B 62 (2000) 7138-7143.

6. K. Moriguchi, S. Munetoh, A. Shintani, Phys. Rev. B 64 (2001) 195409.

7. G. S. Nolas, C. A. Kendziora, J. Gryko, J. Dong, C. W. Myles, A. Poddar, O. F. Sankey, J. Appl. Phys. 92 (2002) 7225-7230.

8. G. S. Nolas, M. Beekman, J. Gryko, G. A. Lamberton Jr., T. M. Tritt, P. F. McMillan, Appl. Phys. Lett. 82 (2003) 910-912.

9. A. Ammar, C. Cros, M. Pouchard, N. Jaussaud, J.-M. Bassat, G. Villeneuve, M. Duttine, M. Ménétrier, E. Reny, Solid State Sci. 6 (2004) 393-400.

10. L. Krishna, L. L. Baranowski, A. D. Martinez, C. A. Koh, P. C. Taylor, A. C. Tamboli, E. S. Toberer, CrystEngComm 16 (2014) 3940-3949.

11. M. Pouchard, C. Cros, Science 150 (1965) 1713-1714.

12. K. A. Kovnir, A. V. Shevelkov, Rus. Chem. Rev. 73 (2004) 923-938.

13. M. Beekman, G. S. Nolas, J. Mater. Chem. 18 (2008) 842-851.

14. J. L. Cohn, G. S. Nolas, V. Fessatidis, T. H. Metcalf, G. A. Slack, Phys. Rev. Lett. 82 (1999) 779-782.

15. M. Christensen, A. B. Abrahamsen, N. B. Christensen, F. Juranyi, N. H. Andersen, K. Lefmann, J. Andreasson, C. R. H. Bahl, B. B. Iversen, Nature Mat. 7 (2008) 811-815.

16. D. Connétable, V. Timoshevskii, B. Masenelli, J. Beille, J. Marcus, B. Barbara, A.M. Saitta, G.-M. Rignanese, P. Mélinon, S. Yamanaka, X. Blase, Phys. Rev. Lett. 91 (2003) 247001.

17. S. Yamanaka, E. Enishi, H. Fukuoka, M. Yasukawa, Inorg. Chem. 39 (2000) 56-58.

18. A. M. Guloy, R. Ramlau, Z. Tang, W. Schnelle, M. Baitinger, Y. Grin, Nature (London) 443 (2006) 320-323.

19. M. Beekman, M. Baitinger, H. Borrmann, W. Schnelle, K. Meier, G. S. Nolas, Y. Grin, J. Am. Chem. Soc. 131 (2009) 9642-9643. 
20. H. Horie, T. Kikudome, K. Teramura, S. Yamanaka, J. Solid State Chem. 182 (2009) 129-135.

21. S. Stefanoski, M. Beekman, W. Wong-Ng, W. P. Zavalij, G. S. Nolas, Chem. Mater. 23 (2011) 1491-1495.

22. R. Himeno, T. Kume F. Ohashi, T. Ban, S. Nonomura, J. Alloys Comp. 574 (2013) 398-401.

23. A. D. Martinez, L. Krishna, L.L. Baranowski, M. T. Lusk, E. S. Toberer, A. C. Tamboli, IEEE J. Photovoltaics 3 (2013) 1305-1310.

24. S. Stefanoski, C. D. Malliakas, M. G. Kanatzidis, G. S. Nolas, Inorg. Chem. 51 (2012) 8686-8692.

25. L. L. Baranowski, L. Krushna, A. D. Martinez, T. Raharjo, V. Stevanvic, A. C. Tamboli, E. S. Toberer, J. Mat. Chem. C 2 (2014) 3232-3939.

26. F. Ohashi, Y. Iwai, A. Noguchi, T. Sugiyama, M. Hattori, T. Ogura, R. Himeno, T. Kume, T. Ban, S. Nonomura, J. Phys. Chem. Solids 75 (2014) 518-522.

27. T. Kume, Y. Iwai, T. Sugiyama, F. Ohashi, T. Ban, S. Sasaki, S. Nonomura, Phys. Status Solidi C 10 (2013) 1739-1741.

28. J. M. Cowley, A. F. Moodie, Acta Cryst. 10 (1957) 609-619.

29. R. A. Matula, J. Phys. Chem. Ref. Data 8 (1979) 1147-1298.

30. P. D. Desai, H. M. James, and C. Y Ho, J. Phys. Chem. Ref. Data 13 (1984) 1131-1172. 
Table I. Si clathrate samples prepared in this study.

\begin{tabular}{cccc} 
Sample No. & Si wafer & $\begin{array}{c}\text { Electrode } \\
\text { (top/bottom) }\end{array}$ & $\begin{array}{l}\text { Iodine } \\
\text { treatments }\end{array}$ \\
\hline 1 & Intrinsic & - & No \\
2 & Intrinsic & - & 3 times \\
3 & n type & ITO/Al & 3 times \\
4 & p type & ITO, $\mathrm{Ag} / \mathrm{Al}$ & 6 times \\
\hline
\end{tabular}

Figure 1. Photographs of the $\mathrm{Na}_{x} \mathrm{Si}_{136}$ film grown on the surface of wafer before (a) and after wiping by a cotton bud (b). In (c), the bottom panel corresponds to the Raman spectrum in region A. The top panel in (c) shows reported Raman spectra for powder Si clathrates in which the $\mathrm{Na}$ content was identified.

Figure 2. EDX spectra obtained for Sample 2. The peak corresponding to $\mathrm{Na}$ disappeared by $\mathrm{I}_{2}$ treatments.

Figure 3. Grazing-incidence XRD pattern measured for Sample 4. The grazing angle $\omega$ was set to $1^{\circ}$. The asterisks correspond to the peaks from Ag, which was deposited on the sample for electrical measurements. The bar charts at the figure bottom show powder XRD patterns of $\mathrm{Na}_{8} \mathrm{Si}_{46}$ (PDF card 01-089-5534), $\mathrm{Na}_{1} \mathrm{Si}_{136}$ (PDF card 01-089-5535), and d-Si (PDF card 00-005-0565).

Figure 4. Cross-sectional TEM images of the guest-free Si clathrate thin films on Si(111) wafer (Sample 2). (a) a low-resolution TEM image, (b) and (c) high-resolution TEM (HRTEM) images of Si clathrate, and (d) a HRTEM image around the boundary between the Si clathrate and the Si wafer. The inset of (c) is the theoretical image simulated under the clathrate structure. The insets of (d) show the results of the fast Fourier transformation (FFT) of the lattice patterns, that is, the electron diffraction pattern of the Si clathrate and the wafer.

Figure 5. I-V characteristics measured for (a) $\mathrm{Ag} / \mathrm{Si}_{136} / \mathrm{Ag}$, (b) $\mathrm{Ag} / \mathrm{Si}_{136} / \mathrm{p}-\mathrm{Si} / \mathrm{Al}$, (c) ITO/Ag/ $\mathrm{Si}_{136} / \mathrm{p}-\mathrm{Si} / \mathrm{Al}$, and (d) $\mathrm{Ag} / \mathrm{Si}_{136} / \mathrm{n}-\mathrm{Si} / \mathrm{Al}$ systems. In (c), circles and crosses correspond to the data measured with and without light illumination of AM1.5, respectively. 
Fig. 1

\section{Sample 1}

Substrate Powder (Region B)
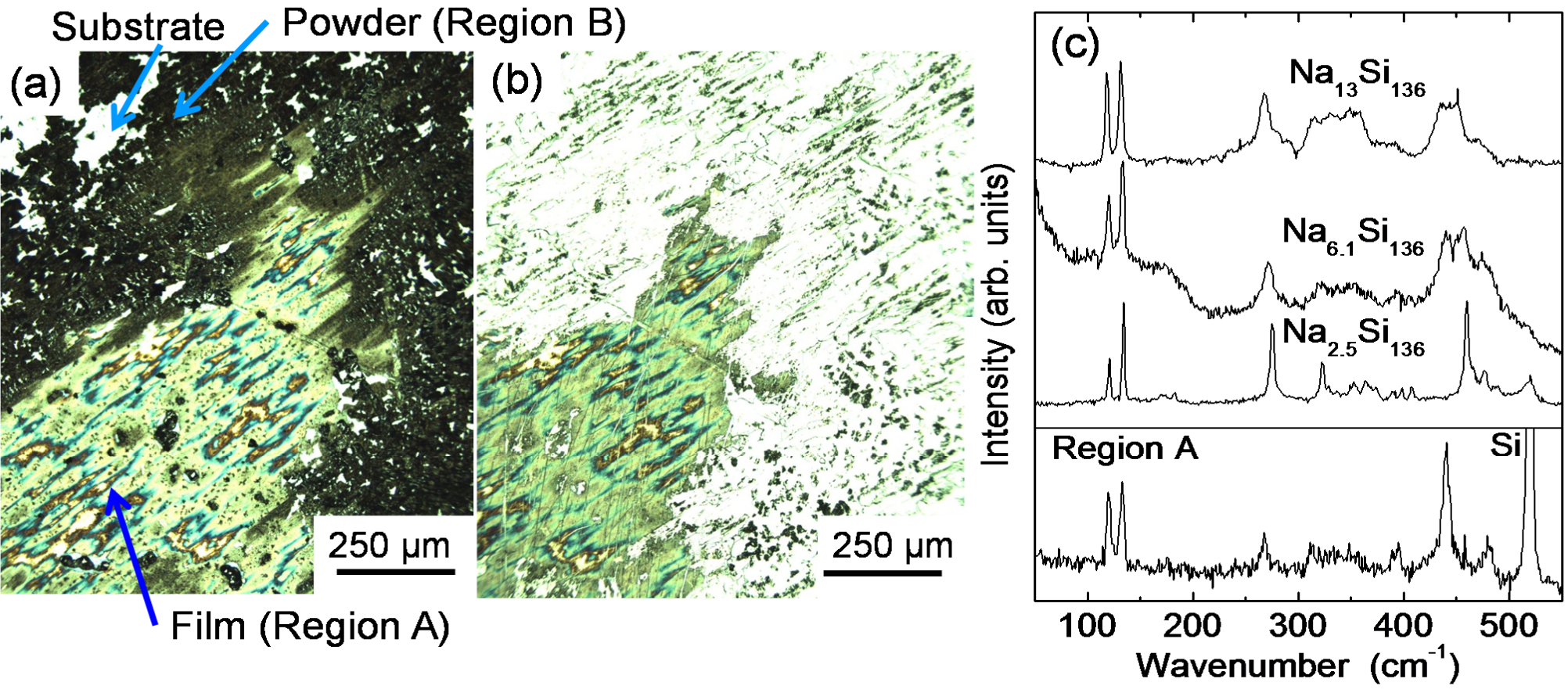
Fig. 2

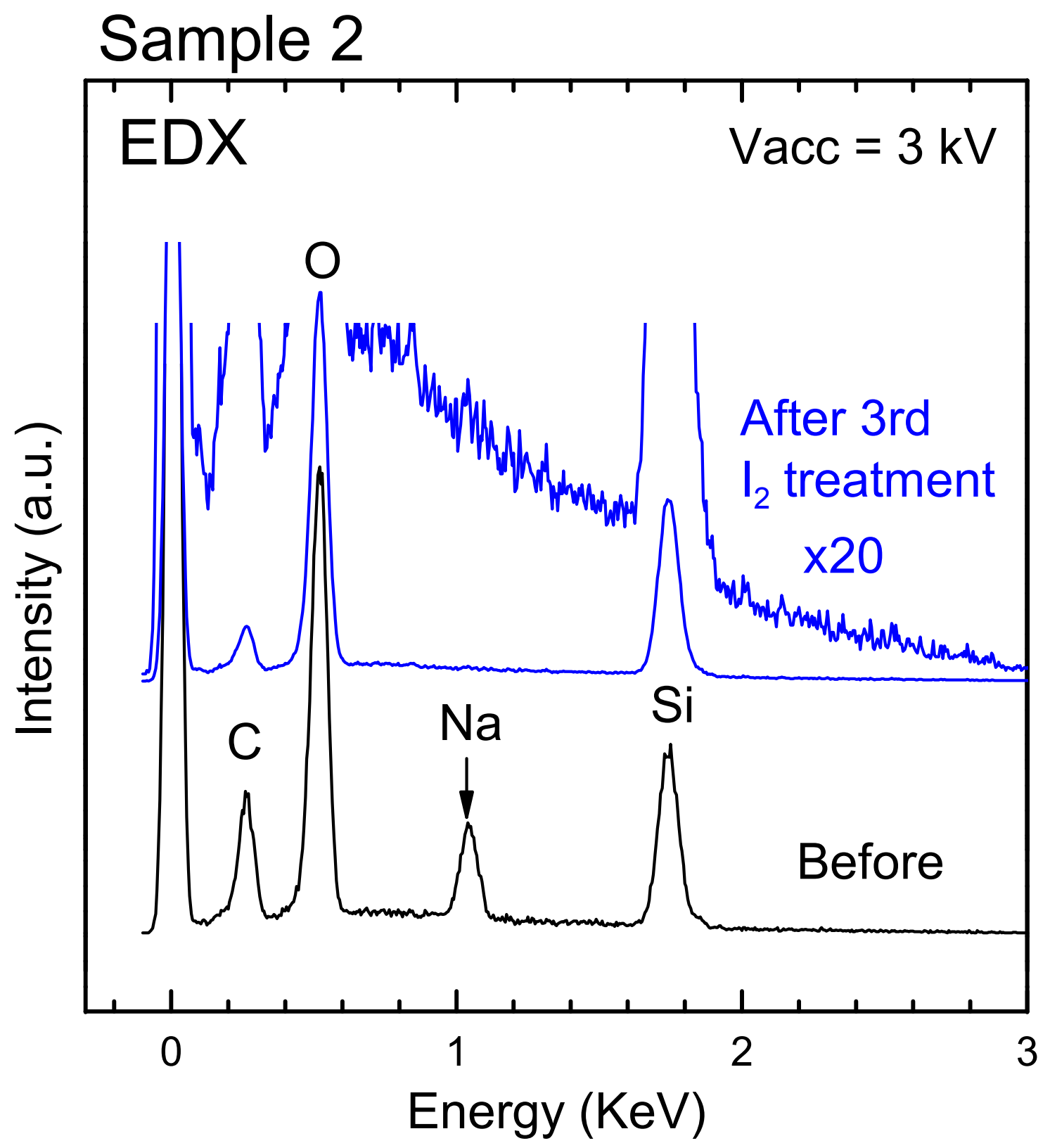


Fig. 3

Sample 4 XRD $\quad \mathrm{Cu} \mathrm{K \alpha}$

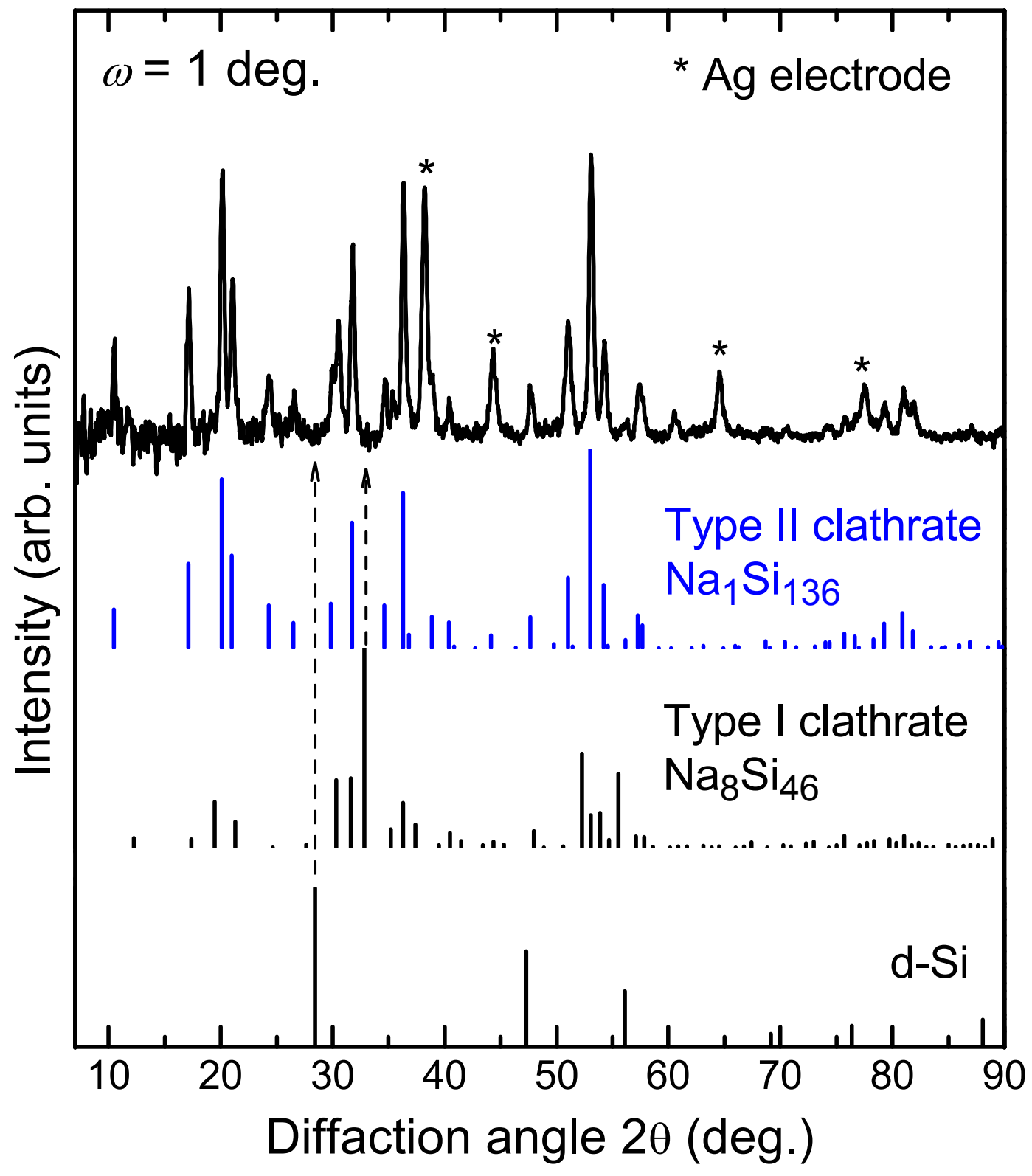


Sample 2
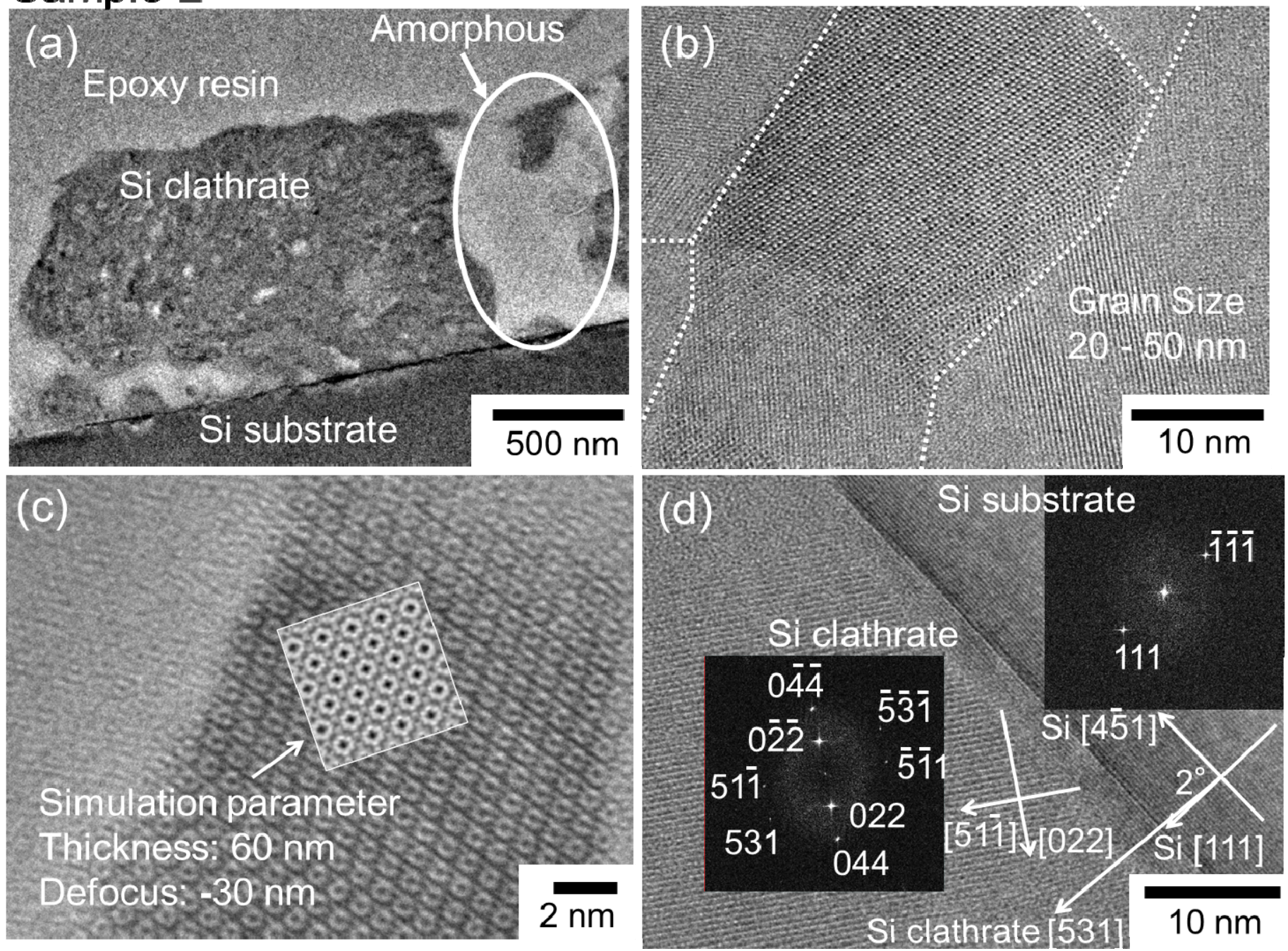

Fig. 4 
Fig. 5
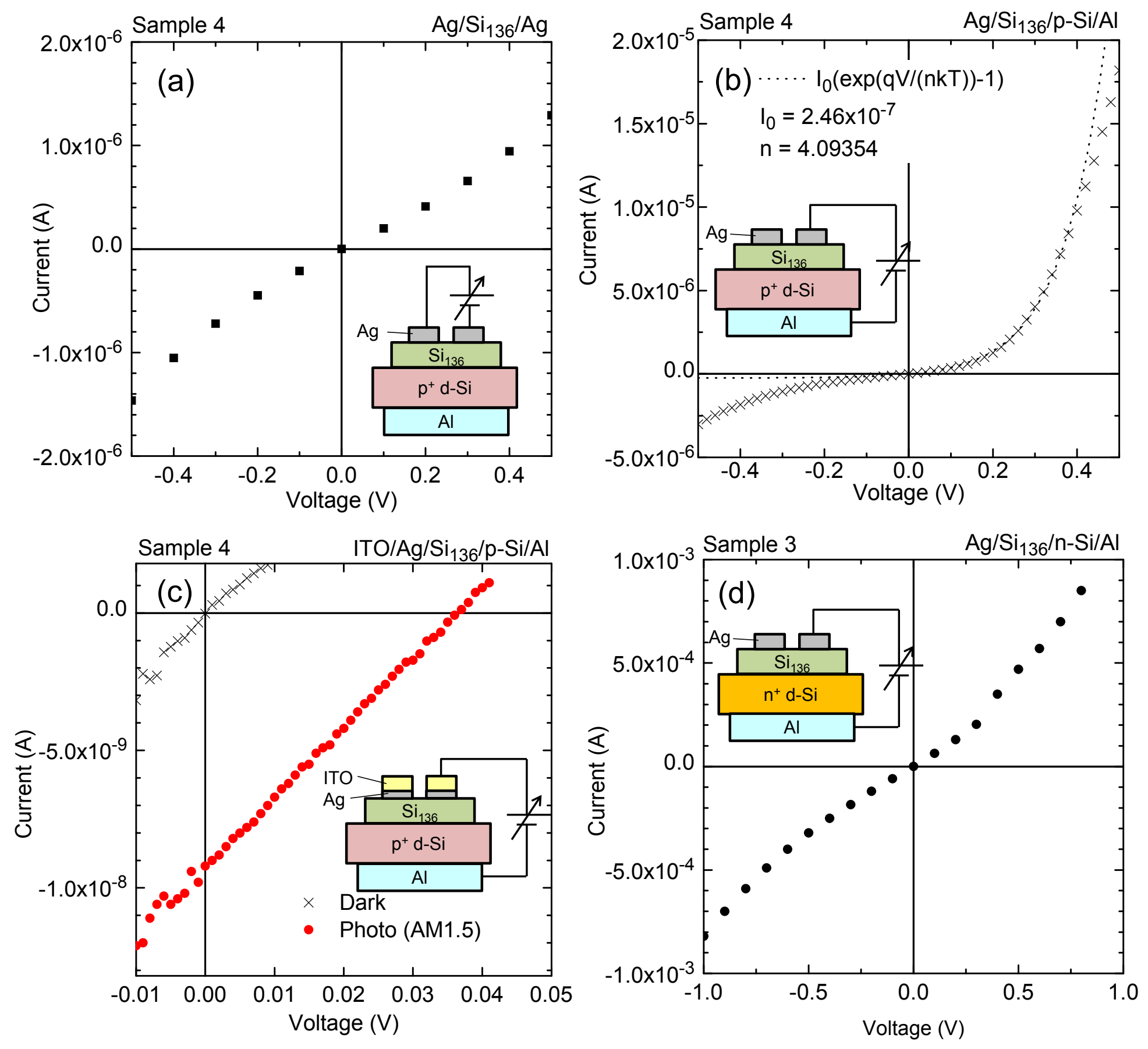